\title{
Have we Failed Informing the Population the Negative Health Effects of Alcohol? Lessons from the Tobacco Campaigns
}

\section{Laura E Moreno-Luna*}

Departamento de Clínicas Médicas, Centro Universitario de Ciencias de la Salud, Universidad de Guadalajara, Guadalajara, Jalisco, México

It is well known that alcohol abuse and alcohol dependence are chronic diseases, that even in the $21^{\text {st }}$ century, they might be controlled but not cured. There is growing disillusionment with the actual model of interventions and the constant failure of long term addiction recovery. Alcohol abuse is the origin of some of the most serious health problems worldwide: Alcoholic Liver Disease (ALD), cirrhosis and Hepatocellular Carcinoma (HCC). In many subjects, diverse treatments are intended before they present a liver disease: psychiatric therapies, supporting groups, clinics, medications, alternative treatments and all of them share frequent failure rates. Alcohol affects the liver depending on the dose and duration of use or abuse [1]. It has been previously reported that among heavy drinkers $90 \%$ to $100 \%$ will show histological evidence of fatty liver but only 10 to $35 \%$ will develop alcoholic hepatitis and $8 \%$ to $20 \%$ will develop cirrhosis $[2,3]$.

Do people really know these data? Is the general population informed about the risks to health related to alcohol abuse? Nowadays, campaigns against alcohol are mainly directed to prevent social problems such as accidents, unemployment, family disintegration and others, but the instruction of the individual health problems related to alcohol is being neglected. How often campaigns mention the chances of getting a severe and irreversible liver disease? Are we doing enough? The answer is no. Most people ignore the amount and frequency of alcohol that can cause a chronic liver disease, cirrhosis and/or cancer furthermore, the effects of alcohol in other organs. In many countries, liver diseases related to alcohol occupy between the first 10 causes of morbidity and mortality. The World Health Organization reported that unfortunately in some countries such as Brazil, Czech Republic and Denmark between others, alcohol consumption is increasing. Ideally, the actual trend in the whole world should be a steady decrease in consumption as it is happening in Argentina, France, Italy and other countries. What results were obtained after the intense worldwide campaigns against tobacco? Smoking rates are declining since the last two decades. Advertising in the mass media allows to repeatedly exposing the population to messages about the negative effects of tobacco use and the benefits of quitting. The world needed campaigns like that to significantly decrease the tobacco use. Even if it remains widespread, the strict application of laws is helping and all the population has a better understanding about the negative effects of tobacco smoking. Why the same is not done with alcohol? At the present times, the understanding of the role of genetic factors in the susceptibility to alcohol dependence and alcohol abuse is improving [4]. Several brain and liver genes have been studied. The combination of these genes may modify the risk or protection against alcohol and the amount of alcohol metabolized in the liver and the susceptibility to liver damage. Even though, the exact genes for the development of ALD cirrhosis or HCC have not been defined, these genes are still under study and they are not available in clinical laboratories, and the interpretation is still being debated. However, alcohol abuse and alcohol dependence have a multifactorial origin, and it has also been shown that the environment occupies a very important position in alcoholics. How much is environment and genetics influencing alcoholism? In the meantime bigger efforts should be done in preventing the population of the enormous risks to health that alcohol poses. Our main goals in the short future should be: people from every country should know how risky is to abuse alcohol to the liver and other organs, the governments should design stricter laws regarding alcohol disponibility and use and ensure that the goals are achieved.

In conclusion, many questions arise from these reasoning: Will people change the view to alcohol abuse if they really know the negative effects to their health? Will informed subjects have the same risks of alcohol abuse and alcohol dependence, independently from their genes?

\section{References}

1. Lieber CS (2000) Alcoholic liver disease: new insights in pathogenesis lead to new treatments. J Hepatol 32: 113-128.

2. Teli MR, Day CP, Burt AD, Bennett MK, James OF (1985) Determinants of progression to cirrhosis or fibrosis in pure alcoholic fatty liver. Lancet 346: 987 990.

3. Orholm M, Sørensen TI, Bentsen K, Høybye G, Eghøje K, et al. (1985) Mortality of alcohol abusing men prospectively assessed in relation to history of abuse and degree of liver injury. Liver 5: 253-260.

4. Roman S, Zepeda-Carrillo EA, Moreno-Luna LE, Panduro A (2013) Alcoholism and Liver Disease in Mexico: Genetic and Environmental Factors. World J Gastroenterol in press.
*Corresponding author: Laura E Moreno Luna, Universidad de Guadalajara, Guadalajara Jalisco México, CP 44500, Tel: (33) 159163 82, (33) 159163 83, (33) 316760 59; E-mail: morenoluna.laura@gmail.com

Received October 26, 2013; Accepted November 01, 2013; Published November 12,2013

Citation: Luna LEM (2013) Have we Failed Informing the Population the Negative Health Effects of Alcohol? Lessons from the Tobacco Campaigns. J Liver 2: e107. doi:10.4172/2167-0889.1000e107

Copyright: (c) 2013 Luna LEM. This is an open-access article distributed unde the terms of the Creative Commons Attribution License, which permits unrestricted use, distribution, and reproduction in any medium, provided the original author and source are credited. 